\title{
TEORÍA DE LA NOVELA GÓTICA
}

\author{
MIRIAM LÓPEZ SANTOS \\ Universidad de León
}

\begin{abstract}
Resumen:
El presente artículo sistematiza, desde el punto de vista de la teoría literaria, las características que definen el género de la novela gótica. Un acercamiento a las particularidades que la determinan (argumento, personajes, narrador y coordenadas espacio-temporales) permitirá establecer y fijar con mayor precisión las fronteras con respecto a géneros cercanos y paralelos en nacimiento (la novela sentimental y la novela histórica), así como sentar las bases para posteriores análisis de novelas concretas.
\end{abstract}

Palabras clave: Teoría, novela gótica, literatura fantástica, terror, estética de lo sublime.

\begin{abstract}
:
The present article systematizes, from the viewpoint of literary theory, the characteristics that define the gothic novel genre. A close look at the special features that determine it (plot, characters, narrator, space-time coordinates) will allow us to establish and fix more accurately the limits with regards to close and parallel genres rising at the time (sentimental novel and historic novel), as well as laying down the foundations for further analysis of particular novels.
\end{abstract}

Key words: theory, gothic novel, fantastic literature, terror, sublime aesthetics

\section{Prefacio}

$\mathrm{N}$ uestra pretensión en este trabajo pasa por volver la mirada hacia un género que ha sido punto menos que denostado por gran parte de la crítica literaria: hablamos de la novela gótica. En nuestro intento de sistematización, estableceremos, en primer lugar, un conjunto de características que hemos derivado de la lectura de las novelas cumbres del mismo ( $E l$ castillo de Otranto, Los misterios de Udolfo y El Monje). Las mismas se encuentran fundamentalmente en el argumento, los personajes, el narrador y las coordenadas espacio-temporales. Somos conscientes, no obstante, de que se podrían haber elegido otros parámetros de observación, de la misma manera que no ignoramos que la elección de estos y no de otros decantará nuestra postura y nos ayudará a fijar unos esquemas teóricos susceptibles de aplicación 
en cualquier posterior análisis del género gótico tanto dentro de nuestras fronteras ${ }^{1}$ como fuera de las mismas.

Pero hablando de novela gótica, no podemos obviar un hecho harto conocido; en efecto, se viene advirtiendo, ya desde sus inicios, la acusación de un género simplista y falto de calidad. Sin embargo, no solo la censura, como se ha creído, fue la responsable de este estado de cosas; la propia crítica literaria de la época contribuyó sobremanera a obstaculizar un camino, ya de por sí extremadamente dificultoso. Debido a ello quizás, la consideración de la estructura de la novela gótica no haya variado un ápice desde que fuera divulgada, una vez multiplicado el número de obras de manera desconcertante, en un periódico inglés de la época:

Tómese un viejo castillo medio en ruinas; un largo corredor lleno de puertas, varias de las cuales tienen que ser secretas; tres cadáveres aún sangrantes; tres esqueletos encadenados; una vieja estrangulada y con varias puñaladas en el pecho, salteadores y bandidos a discreción; fantasmas ululantes; una dosis suficiente de susurros, lamentos ahogados y horrísonos estruendos. Mézclese todo, agítese bien y escríbase: el cuento esta listo. (Pillen, 1967: 13).

Aunque este es a trazo grueso el esquema narrativo gótico con sus principales características, que, en principio, reducirían considerablemente las posibilidades de innovación y diversificación, la vasta producción existente demuestra el infinito abanico de variantes que se pueden originar. Es más, la complejidad temática y estructural que esconde y la diversidad de interpretaciones teóricas a las que ha dado lugar apuntan en la dirección de una novela abundante en matices y en la que cada elemento del escenario y de la acción es introducido para contribuir a crear la impresión de ilimitado terror y de suspense palpitante. Solo desde esta perspectiva nos es posible comprender, entonces, la riqueza de estas novelas: sus atormentados personajes, el tratamiento dado a la mujer, el espacio literario, el vampirismo o el punto de vista del narrador ${ }^{2}$.

\footnotetext{
${ }^{1}$ Es fácilmente constatable en las diversas historias de la literatura una gran carencia en los estudios sobre la novela fantástica-gótica española, en particular, y sobre toda la producción novelística del siglo XVIII, en general.

2 Asimismo, por ser predecesora en muchos aspectos, debe considerarse como el punto de partida de la novela, en el sentido en que el término es entendido en la actualidad. "La conciencia de género es, a la vez, un elemento importante extraliterario para configurar las características a las que deberán ajustarse las producciones literarias que aspiren a formar parte de este grupo" (Álvarez Barrientos, 1991: 155). Conviene advertir, por ello, antes de introducirnos en las peculiaridades de esta narrativa, que su nacimiento fue paralelo al de otras dos modalidades de novela: la sentimental y la histórica y que tomaron conciencia de género desde sus orígenes. Evidentemente, un origen común prefigurará unas características, al menos, similares. Sin embargo y a pesar de las afinidades entre las mismas, fueron, como era de esperar, las disimilitudes las que establecieron las fronteras entre unas y otras. Pues, por una parte, aunque bajo la novela gótica subyace una teoría de la historia, se apropia de ella, frente a la novela histórica, precisamente para rehuirla y afirmar mejor así su anacronismo; de la misma manera que a pesar de que las implicaciones de las novelas sentimentales sean melodramáticas o, incluso, trágicas su intención es revelar el poder de la luz y de la redención, insistir en que la virtud, aunque no prospere en todos los casos, al menos acaba siempre por triunfar. En cambio,
} 


\section{Componente argumental}

El grueso de la crítica ha centrado sus esfuerzos, obviando otros aspectos de igual o similar trascendencia, en el estudio del elemento temático. De hecho, la mayoría de los trabajos que hemos podido consultar toma como punto de partida el argumento a la hora de enfrentarse al análisis de cualesquiera sean los componentes de dicha novela. Bien es cierto, por otro lado, que el tratamiento que los novelistas góticos han otorgado a la acción resulta del todo fundamental en este tipo de relatos. Se trata, en el fondo, de narrar historias, no de recrearse en la psicología de los personajes, que son más bien tipos al servicio de los acontecimientos que auténticos creadores de la trama.

Sin embargo, la complejidad de los temas y la variedad de posturas tomadas por los investigadores, lejos de favorecer su estudio, dificultan en demasía el análisis de este componente. Se tiende a optar ${ }^{3}$, fundamentalmente, por agrupar temas de manera aleatoria, olvidando establecer un vínculo común entre los mismos. Nosotros, sin pretender menospreciar aquellas teorías y tomando como base esta innegable trascendencia, hemos organizado el componente argumental de las novelas góticas de acuerdo a dos principios que consideramos, por otro lado, indispensables en el complejo entramado de la novela gótica: la lógica narrativa y los motivos recurrentes.

\subsection{Lógica narrativa de las novelas góticas}

La percepción de la literatura gótica implica una manera de leer y estructurar el relato atenta a una consideración más compleja y global de la realidad, que es algo mucho más misterioso, inquietante y perturbador de lo que puede parecer a simple vista (Barella, 1994: 11).

Así es; antepasado directo de la novela policíaca ${ }^{4}$, la novela gótica está construida como una sucesión de enigmas a los que el protagonista está obligado a enfrentarse. Este entra en un universo en que cada objeto, cada situación, cada personaje, incluso, parecen esconder algo: un pasado oculto, un secreto disperso, fragmentario y quimérico que guarda relación con los acontecimientos; en definitiva, una causalidad oculta (Ramos Gómez, 1988: 34). Desde el comienzo sabemos que hay algo misterioso, ininteligible, algo que se manifiesta fundamental, pero que se nos presenta como desconocido.

Esta serie de enigmas sale a la realidad poco a poco gracias a las fuerzas nocturnas que son los sueños, a situaciones fortuitas e imprevistas y a una serie

el principal empeño de la novela gótica, aunque tenga una final feliz, será siempre describir el terrible poder que ejercen en el mundo las tinieblas.

${ }^{3}$ El estudio riguroso del componente argumental de las novelas góticas corresponde a autores como Penzould o Killen.

${ }^{4}$ El investigador Fereydonum Hoveyda, uno de los mayores especialistas en este género, sostiene que la novela policíaca, como relato construido a partir de acontecimientos fantásticos, es un claro precedente de la novela gótica. (Historia de la novela policíaca, Madrid, Alianza Editorial). De hecho, los textos fundadores de la novela policíaca (Blazar, Gaboriau y Poe) fueron redactados por escritores de formación "gótica" y en una perspectiva híbrida, como Los crímenes de la calle Morgue de Poe, obra catalogable en los dos géneros. 
de apariciones que sufren y soportan los personajes. Se produce, entonces, y según Molina Foix, una tensión entre lo diurno y lo nocturno (2003: 17) que rompe el esquema tranquilizador y "nuestros personajes viven la profunda inadecuación del esquema diurno de la realidad, sin estar en posesión de la clave nocturna". Durante el día, permanece el misterio, acrecentándose su efecto; la noche, por el contrario, saca a la luz un nuevo episodio del secreto que permanecía oculto desde el inicio de la novela.

El relato gótico se nos muestra como cerrado e interminable al mismo tiempo, pues la lógica narrativa consiste, asimismo, en retrasar la revelación última que pondrá fin a la aventura del protagonista y al texto. "La conclusión restablece el transcurrir normal del tiempo y de la vida, marcándole un punto final, pero a lo largo del relato, fenómenos, prodigios, pruebas, terrores y huidas se pueden multiplicar hasta el infinito." (Ramos Gómez, 1988:36).

Como señala Matilde en El castillo de Otranto "no estoy segura de cual es el fatal secreto" (Walpole, 1982: 29); secreto este que permanece oculto y que solo con el final de la novela será desenmascarado ante la atenta mirada de protagonistas y público lector.

Se trata, en suma, de una búsqueda hermenéutica que prefigura la del propio lector y que constituye el verdadero proceso de la novela. El lector, como el protagonista, solo puede entender la historia, rellenar "vacíos" $\mathrm{y}$, decantar, en definitiva, cada suceso extraño bien del lado de la realidad o bien del lado de lo fantástico o sobrenatural volviendo sobre sus pasos y reinterpretando las escenas que le han sido referidas. De ahí que el relato gótico sea inseparable de la subjetividad al basarse este en la dimensión personal de unos personajes, incapaces de distinguir lo posible de lo imposible.

El relato dura, entonces, mientras dura el misterio; cuando la realidad o la explicación se imponen, el relato llega a su fin. Así, se revela, por ejemplo, al concluir El castillo de Otranto, que Teodoro es el verdadero heredero del principado. La espeluznante lucha que mantenía con las fuerzas de la noche ha concluido, el miedo que imperaba se ha desvanecido y la razón acaba por imponerse definitivamente.

Contribuye, del mismo modo, a crear esta ambigüedad y confusión, desde el descubrimiento de un manuscrito mohoso que permanecía oculto ${ }^{5}$, hasta la frecuente narración en primera persona y a veces en forma epistolar, que se intercala con el narrador omnisciente, sin olvidar tampoco esa compleja escenografía de elementos espeluznantes. Sin embargo, será la inclusión de poemas y otros cuentos dentro de la estructura general, por un lado, y la personalidad cambiante de los personajes, por otro, los elementos que con mayor fuerza contribuyen a esta lógica, complicando aún más el devenir de los acontecimientos y la búsqueda final del enigma: optará por una u otra opción,

\footnotetext{
${ }^{5}$ El castillo de Otranto comienza con un prólogo en el que el narrador nos informa de la verdadera génesis de la obra. En realidad y según nos refiere él mismo "la obra que se ofrece a continuación se encontró en la biblioteca de una familia católica del norte de Inglaterra. Se imprimió en Nápoles con caracteres góticos en el año 1529, sin que conste cuando se había escrito." (Walpole 1982: 15).
} 
de acuerdo con la posición que haya tomado con respecto al tratamiento del elemento fantástico.

Así pues, hasta los propios personajes, tal y como nos son presentados al comienzo del relato, son otros. Si tomamos como ejemplo El castillo de Otranto, vemos que el señor feudal es, en realidad, un usurpador, el piadoso monje un noble caballero y el joven campesino, el hijo y heredero legítimo de este. La identidad es cambiante, como lo es la personalidad (el protector de Isabella se convierte más tarde en su perseguidor), como lo son los objetos y como lo es, incluso, el lenguaje, que da lugar a continuos malentendidos.

La complejidad narrativa aparece apoyada también en una serie de relatos que se superponen provocando cierta sensación de caos. Así es, las novelas góticas destacan por la superposición de historias, a veces, de diferente índole y que, en principio, no parecen mantener relación alguna con la trama inicial. Sin embargo, no responden a un motivo casual ni aleatorio, sino que esta estructura de caja china entronca directamente con la esencia misma de la novela gótica: la búsqueda del exceso. Esta tendencia al exceso, a la repetición casi obsesiva de relatos y situaciones terroríficas es, en realidad, un intento de aumento de la tensión narrativa. En El monje se aprecia perfectamente. Lewis opta por presentarnos, junto a la historia del monje Ambrosio, el fatídico amor de Ramón por la desdichada Inés, permitiéndose, además, incluir, a su vez, en esta última el relato de la monja ensangrentada y como aderezo, añade todo tipo de lances góticos a cual más exagerado. Las historias se entrelazan, entonces, para favorecer la tensión del relato y contribuir a la confusión de personaje y lector.

El relato gótico, en definitiva, está marcado por el misterio y la ambigüedad. Si a esta fascinación por crear tensión se le añade una sensación de temor y maldad, surge un compuesto de emoción intensa y provocación imaginativa que supondrá la auténtica clave de estas narraciones.

\subsection{Motivos recurrentes}

Como ya señaláramos previamente, hemos optado por eludir cualquier clasificación temática de la novela gótica; por el contrario, sí consideramos imprescindible describir la serie de elementos constitutivos de este mundo gótico; los motivos, por emplear la terminología de análisis que desarrolla Garrido Domínguez, que organizan, de manera general, la estructura de estos relatos. Lo que nos interesa es señalar que nos hallamos ante motivos de un mismo campo asociativo con los que el autor aspira a conseguir "el sentimiento y la sensación del miedo". El principal eje constituyente de estas novelas es, de acuerdo con nuestra argumentación, el miedo. En torno al miedo, giran todos los acontecimientos que deben o no ser explicados por los protagonistas de estos relatos y, alrededor de este, se plantea el doble juego, la dialéctica entre la razón y la sinrazón de la literatura gótica.

Es el miedo, sin lugar a dudas, la emoción más antigua y más intensa de la humanidad (Lovecraft, 1989: 7) y fue precisamente Burke el primero que, percatándose de este hecho, supo ver los efectos del miedo y su contribución a lo sublime cuando afirmó: 
No hay pasión que robe tan determinantemente a la mente todo su poder de actuar y razonar como el miedo. Pues el miedo, al ser una percepción del dolor o de la muerte, actúa de un modo que parece verdadero dolor. [...] todo lo que es terrible en lo que respecta a la vista, también es sublime [...]; es imposible mirar algo que pueda ser peligroso, como insignificante o despreciable [...]. Es el terror la fuente de todo lo sublime (Burke, 2005: 86-87)

El miedo se alza, según este filósofo, como condición indispensable para poder provocar el sentimiento de lo sublime, puesto que recordamos el dolor y la amenaza de muerte más vivamente que el placer (Lovecraft, 1989: 9); dicho de otro modo, el miedo no suscitará la intención deseada en el lector si este no dispone de un verdadero sentimiento de lo sublime. Y, por supuesto, cuanto más completa y unificadamente consiga un relato sugerir dicha sensación, más perfecto será como obra de arte de este género (Lovecraft, 1989: 12).

Un miedo estético que viene a ser reflejo y resultado de ese conjunto de miedos históricos que convergen en el recuerdo de un antiguo régimen de opresión y persecución que a todos amenazaba y que impedía, por lo mismo, una entrada en la modernidad, libre de todo perjuicio. Por lo tanto, toda completa exploración de la novela gótica exigirá una exhaustiva exploración del sentimiento del miedo, tanto físico como mental y un descubrimiento de las varias formas en que el terror se abre paso en la literatura.

Siguiendo, entonces, a Burke, gran conocedor y teórico de esta nueva estética de lo sublime, $y$ teniendo presente el poligenismo causal que dio lugar a este género, proponemos una clasificación temática que parta del punto de vista del miedo, porque el miedo es "algo más que un tema o una actitud, puesto que influye en la forma, el estilo y las relaciones sociales del texto" (Molina Foix, 2003: 25). Se trata de un elemento constitutivo y estructurador, indispensable, clave y definitorio de este tipo de novelas. Proponemos, en definitiva, una clasificación que consideramos abarcará un mayor número de campos y permitirá un estudio más sistemático de los mismos. Así pues, de acuerdo con las indicaciones previas de Burke, hemos dividido este gran eje argumental que es el miedo en los dos elementos primordiales responsables de provocarlo: por una parte, el dolor y, por otra, la muerte. Partiremos, entonces, de estos dos grandes pilares temáticos que segmentaremos, a su vez, en una serie de motivos que contribuirán a completarlos; motivos, unos y otros, que deben aparecer en su justa medida, de lo contrario, si resultan excesivos o inverosímiles no lograrán provocar en los lectores el efecto deseado.

\subsubsection{Miedo a la muerte}

El miedo a la muerte, esa que nos acecha inexorable desde nuestro nacimiento, nació con el ser humano. Por lo que a esta se refiere y de acuerdo con las diferentes épocas históricas, el hombre ha intentado transformarla, dominarla, obviarla, negarla o aliarse con ella. La ideología dominante en el siglo XVIII optó por poner entre paréntesis la realidad de morir, pues en su afán por el progreso absoluto y la sabiduría suprema no cabía problema necrofilosófico alguno. “¿Cómo no iba a resurgir, de forma obsesiva, 
desmesurada el terror más viejo del hombre?" (Ramos Gómez, 1988: 88). Sin embargo, es obvio que si el cadáver en sí mismo es del todo inofensivo, entonces, ¿en dónde debemos buscar este profundo terror?, ¿hubo causantes reales de difundirlo?

El intenso miedo a la muerte, que trajo consigo la popularidad de esta literatura, debe rastrearse en la estudiada presión ejercida por el racionalismo sobre las estructuras religiosas que acabaría por convertir a esta en un tema tabú dentro de la sociedad. La muerte no puede ser, en ningún caso, y frente a la presión racionalista, obviada o eludida, porque, al fin y al cabo, la muerte es tan necesaria a la vida como esta lo es para aquella.

Resulta entonces evidente que la muerte aterraba y aterra, y del miedo a la muerte al miedo a los muertos no hay más que un pequeño paso. De ahí que el peso de la muerte sea tan grande en los relatos góticos, que se nos muestre presente a cada paso, en cada página. En estas novelas los muertos no desaparecen en la nada, no mueren, sino que se transforman y regresan a nuestro mundo para concluir algo que en vida dejaron por realizar, para satisfacer una venganza o para deshacer lo anteriormente andado.

Como se sabe, los autores de lo fantástico se sienten más cómodos en el incidente y en los efectos narrativos que en el dibujo de los personajes (Lovecraft, 1989: 15). Por este motivo, los seres fantasmales que recorren las novelas góticas cumplirán más un papel argumental, estructural o temático, que el propio que se espera de todo personaje que recorre una novela ${ }^{6}$. Aunque la variedad de motivos es más que evidente (vampiros, esqueletos, figuras satánicas) haremos referencia, a aquel que adquiere mayor relevancia en esta primera etapa del género, por ser un elemento imprescindible en este tipo de relatos góticos iniciales.

El fantasma, ser ambiguo por excelencia, es el arquetipo de los muertos vivientes habitantes del castillo gótico. Su presencia en la literatura es mucho anterior a la aparición del subgénero gótico y se apoyaba en la creencia cristiana de que el regreso de las almas al mundo de los vivos era un fenómeno permitido por Dios y cuyo fin fundamental era la prestación de algún tipo de ayuda a los seres humanos. Sin embargo, esta primigenia concepción positiva del fantasma cambiará con la llegada de la novela gótica. Su aparición va acompañada siempre de un efecto maléfico. De hecho, en el marco de esta novela, estos seres son, ante todo, objetos de terror y como tales son utilizados por los escritores para lograr el deseado efecto de terror. Se sirven de dos tipos de fantasmas. Por un lado, el fantasma que se percibe, se siente, pero en ningún momento se ve y, por otro, el verdadero fantasma, acompañado de toda la parafernalia que se le suponía.

En el primer caso, nos encontramos, en realidad, ante un juego del escritor, un motivo teatral que contribuye a intensificar el suspense del relato. Los

\footnotetext{
${ }^{6}$ De hecho, se trata más bien de motivos imprescindibles que vendrían a incidir en este profundo terror a la muerte, muchos de los cuales fueron tomados de las fuentes orales más primitivas y forman parte de la herencia permanente de la humanidad: el fantasma que se aparece y exige que sean enterrados sus huesos, el amante que regresa del más allá para llevarse con él a su esposa viva, el demonio de la muerte o el hombre lobo son para Lovecraft herederos de toda una rica tradición medieval. (Lovecraft, 1989: 15).
} 
personajes que recelan de los fantasmas (casi siempre los señores de los castillos), son, en realidad, los que mayor miedo sienten hacia los mismos, mientras que los que asumen su existencia, serán aquellos que podrán enfrentarse con más seguridad al miedo que les provocan (los criados y sirvientes). Sin embargo, dado que ciertas novelas exigen una interpretación razonada, muchos de estos fantasmas no son, en realidad, sino personajes disfrazados de los mismos o que por algún motivo se comportan como tales. Junto a los fantasmas reales, entonces, hallamos también a personajes disfrazados de estos. El mejor ejemplo lo encontramos en Los misterios de Udolfo; a lo largo del relato diferentes acontecimientos conducen a personajes y lector a creer en la existencia de fantasmas que vagan y atormentan a los habitantes del castillo. La explicación se precipita, sin embargo, con el desenlace de los acontecimientos: se trataba, realmente, de piratas que, tomando el castillo como guarida, simularon ser fantasmas para evitar ser descubiertos. El personaje que se finge fantasma no se diferencia, entonces, del fantasma real por lo que puede dar lugar a peligrosos equívocos que vendrían a complicar más aún la ya de por sí compleja trama.

Como ya señalamos previamente, junto al fantasma simulado encontramos al verdadero fantasma. Literariamente hablando, la Monja Ensangrentada de El monje es, sin duda, el fantasma más logrado de estas novelas góticas. Se le aparece cada noche al desgraciado Ramón de las Cisternas después de que este le hiciera el voto de ser suyo creyéndola su amada.

No obstante, más allá de la naturaleza del propio fantasma interesa el motivo al que recurren los escritores para hacerles regresar. Normalmente vuelven para cumplir una misión, la naturaleza de esta, no obstante, varía dependiendo del escritor que dibuje sus perfiles. $\mathrm{M}^{\mathrm{a}}$ Teresa Ramos Gómez atribuye connotaciones positivas al retorno de alguno de estos seres del mundo de los muertos. Así, Emily, la protagonista femenina de El castillo de Otranto, lo entiende de la misma manera; ante un crujido del todo extraño que le hizo temer algo sobrenatural, no duda en exclamar: “¿Qué puedo temer? [...]. Si los espíritus de aquellos a los que amamos regresan a nosotros, solo puede ser para felicidad" (Radcliffe, 2001: 173).

Sin embargo, la mayoría de los fantasmas que recorren estas novelas no parecen regresar a la tierra con buenos propósitos; por lo general, vuelven para atormentar a los vivos y suelen obligarles a realizar los deberes que contrajeron hacia ellos, bien para vengarse (normalmente de algún crimen horrible que nadie más conoce), bien para liberarse de su eterna condena7. Es lo que encontramos en el caso referido de La Monja ensangrentada que retorna al mundo de los vivos porque "[...] mis huesos yacen aún insepultos [...] jamás volverá a conocer una noche sin terror a menos que se comprometa a recoger mis pulverizados huesos y depositarlos en la cripta de mi familia en un castillo andaluz (Lewis, 2003: 276).

\footnotetext{
7 La religión cristiana creía en el regreso de los muertos que no habían recibido sepultura en lugar sagrado. Esta creencia se utilizó en el periodo medieval y se perpetuó hasta bien entrado el siglo XVIII, incluso, como castigo más allá de la misma muerte.
} 
Sea cual sea, entonces, la naturaleza de estos fantasmas, parece evidente, por lo dicho hasta ahora, que no puede ni debe elaborarse una novela gótica que no presente una buena dosis de estos seres.

\subsubsection{Miedo al dolor}

Si el miedo a la muerte y a sus consecuencias se condenaba desde las altas esferas de la sociedad iluminista, al considerarse un miedo alejado de toda lógica y basado en una creencia del todo irracional, el miedo al dolor era, frente a aquel, un miedo real. Pertenecía y pertenece, de hecho, al mundo de lo cotidiano $\mathrm{y}$, aunque era evidente que ciertas variantes del mismo se entendían inusuales y extrañas, se movía, no cabe duda, dentro del ámbito de lo probable.

En efecto, las últimas guerras acaecidas en el continente, así como la creciente dureza en las penas y castigos por parte de los tribunales de Inquisición contribuyeron a despertar el hasta entonces adormecido horror por todas las variedades, físicas y psíquicas, del sufrimiento humano. "La cara oscura del Siglo de las Luces" se extendía, pues, frente a lo aparentemente esperable, mucho más allá de unas incómodas novelas oscuras y transgresoras. El régimen del terror era ya imparable.

Los escritores góticos, entonces, una vez recogido todo este bagaje social y cultural, tomaron el tema del dolor humano como motivo recurrente y lo adornaron con todos los horrores de la corrupción física y del pecado, pretendiendo enfrentar al lector con todo aquello que le abominaba y, así, neutralizar su terrible miedo al sufrimiento humano mediante la fascinación.

La serie de motivos que emplean estos escritores en sus novelas giran en torno a dos ejes temáticos: por una parte, el dolor físico y tangible y, por otra, el dolor moral que entroncaría, directamente, con el pecado.

\section{A) El dolor físico}

Como ya apuntáramos más arriba, los escritores góticos vieron en la perversión y en las maldades humanas, el motivo literario ideal, si de lo que se trataba era de infundir profundas dosis de terror en los lectores.

Todas las escenas de barbarie, los innumerables asesinatos y las múltiples torturas y sufrimientos en el fondo de un calabozo, en los lóbregos subterráneos de un castillo o en las prisiones de la Inquisición, relatan la experiencia que tiene el hombre a solas, de la violencia y de la crueldad, e intentan reconciliarle con su imaginación y su subconsciente.

Los escritores se recrean, sobre todo, en dos variantes de este dolor físico: el sadismo, por un lado, y las torturas, por otro. En El Monje encontramos escenas de enorme crueldad. Las semanas de Inés en la cripta del monasterio son una buena prueba de lo que argumentamos. Ella misma lo relata de la siguiente manera: "Cuando recobré el sentido, me encontré sola y en silencio [...]; la pesada cadena que ya había visto con terror, rodeábame la cintura y manteníame sujeta al muro"(Lewis, 2003: 512).

En otros casos la crueldad llega a la total destrucción del ser humano, pues las continuas agresiones convierten el cuerpo en un objeto monstruoso, 
totalmente indescriptible. Esto es lo que ocurre en estos textos donde la muerte se presenta de forma tan macabra que la víctima pierde toda forma humana. La muerte de Ambrosio (Lewis, 2003: 542-543) o la de la Superiora de las Clarisas (Lewis, 2003: 461) en El Monje ejemplifican perfectamente lo señalado.

Sin embargo, conviene especificar que la violencia que nos es presentada en las páginas de estas novelas es puramente verbal, no presenciamos el acto en sí, sino que conocemos, únicamente, el antes y el después del mismo, los antecedentes y las consecuencias; parece lógico, pues la insinuación permite, más allá de las imágenes y las palabras, dejar la puerta abierta a la imaginación del lector; imaginación, ahora sí, sin límites y libre de prejuicios o censuras. La tortura dependería, de acuerdo con esto, de un modo no real sino virtual y así lo señala Todorov: "La violencia se lleva a cabo no solo a través del lenguaje, sino en él. El acto de la crueldad consiste en la articulación de ciertas frases, no en la sucesión de actos efectivos" (Todorov, 1982: 160). A través de estos relatos, entonces, conocemos otra variedad de la crueldad, no referida a quien la practica, sino a quien la imagina y recrea.

\section{A) El dolor moral ${ }^{8}$}

Por el monje Ambrosio conocemos que el miedo al dolor físico, sin embargo, no es tan profundo ni tan perturbador de conciencias como puede serlo el miedo a otra variante de dolor: el dolor moral, dado que tras largas sesiones de intensas torturas "comprobó que los sufrimientos de su cuerpo eran mucho más soportables que los del espíritu" (Lewis, 2003: 256) ${ }^{9}$.

En efecto, las novelas góticas enfrentan al lector a temas prohibidos, temas tabú, logrando que este se identifique con el dolor moral padecido por los protagonistas. Se trata, en definitiva, de contenidos condenados y censurados que, frente a lo esperable, no suelen aparecer, por lo general, expuestos de manera evidente, sino que son tan solo insinuados por sus autores.

A pesar de que los principales motivos de aprensión para las mentes más lúcidas y virtuosas de esta sociedad eran sobre todo el incesto, la homosexualidad y el triángulo amoroso, el primero de ellos constituye la variedad más frecuente, abundando los ejemplos en esta literatura. Se convierte en un motivo esencial e imprescindible, eje constitutivo y estructural de sus tramas, al mismo nivel, incluso, que las diversas variedades de apariciones fantasmales. Sirve, en rigor, para agregar un ingrediente más de temor a los terrores de la usurpación material y al acoso sexual que sufren las

\footnotetext{
8 Estos motivos que hemos agrupado bajo el epígrafe de miedo al dolor moral fueron observados, en su momento, por Todorov y agrupados, por él mismo, bajo la denominación de temas del tú, considerando que se trataba "de la relación del hombre con su deseo y por eso mismo con su inconsciente" (Todorov, 1982: 166).

${ }^{9}$ El poder de la Ciencia y de la Razón parecía insuficiente para contrarrestar el de una Iglesia fortalecida por continuos ataques a su magisterio y que comenzaba a reavivar miedos cervales que el final de la Edad Media parecía haber enterrado; miedos que reaparecerían de la mano de una Inquisición que se sirve del pecado para diferenciar el bien del mal, las conductas socialmente aceptables de las que no lo son.
} 
protagonistas. Su interés, por lo mismo, no era tanto moral, como en épocas anteriores, cuanto psicológico. Fue planteado, por esta razón, como una forma extrema de amor extraordinario, que aparecía siempre en contra de las reglas establecidas. En el incesto encontraron simbolizada estos escritores una repulsa directa a las normas del racionalismo, pero también, como señala Frenzel, la propia sensibilidad narcisista que abría el alma humana, por primera vez, al conocimiento de los abismos y de todo lo satánico (Frenzel, 1980: 188).

La mayor amplitud de desarrollo en la literatura gótica la adquirió el incesto entre hermanos, fuese este consciente o inconsciente. Esta variante de incesto se encuentra planteada en El monje; Ambrosio se enamora, inconscientemente, de su propia hermana, Antonia, a la que rapta, viola y mata, después de haber asesinado a su madre.

En definitiva, hemos intentado hasta aquí sistematizar el componente argumental de la novela gótica que vendría a contradecir, entendemos nosotros, de manera directa, la tendencia, ya comentada previamente, de resaltar su frivolidad por encima de este indiscutible complejo entramado temático.

\section{Actores del relato}

Los preceptos de cada formula narrativa (romance, misterio, melodrama, etc.) exigen que tanto la construcción física y moral de los personajes como las acciones y situaciones producidas por su comportamiento y actuación respondan a modelos convencionales específicos de una determinada cultura y período histórico, y que, sacándolos de este contexto, no tengan la misma significación.

Los personajes que recorren estos relatos son siempre fijos y estereotipados, "personajes marioneta", que llamara Lovecraft, y que fueron introducidos por el creador del género, Horace Walpole. Ello se debe a que estos personajes se encuentran a expensas de la lógica narrativa que terminará no solo por caracterizarlos, sino también por determinar todas y cada una de sus actuaciones. Frente a la razón iluminista, los personajes se descubren inmersos en un mundo cuyas leyes se escapan a su comprensión. Según Ramos Gómez, los personajes de este tipo de relatos

[...] son seres que recorren con esfuerzo el universo sombrío de las cosas visibles y que con angustioso desconcierto comprueban que el mundo no es el descrito por las leyes físicas y matemáticas [...] un mundo que descubren poco a poco como un laberinto, donde las leyes que les permitían explicarse la realidad (leyes del tiempo, del espacio, de la causalidad) pierden su regularidad (Ramos Gómez, 1988: 15).

\subsection{El villano}

Es el verdadero protagonista de las novelas góticas. De hecho, gran parte de estos relatos son recordados por sus malvados héroes dado que ellos encarnan lo que Praz llamó la "agonía romántica", una exaltación extrema de afectos y de pasiones, de sufrimientos y de goces. Carecen del sentido trascendente de lo demoníaco, pero lo suplen siendo especialmente diabólicos en sus características. Se trata de la contracara de la víctima indefensa; un varón cruel, 
tirano, implacable, compendio de todos las vilezas del ser humano que esconde un pasado oscuro e inquietante y que somete continuamente a los personajes femeninos que recorren la obra. Los villanos góticos son seres perturbados y satánicos, herederos de los grandes personajes rebeldes, que están condenados a vivir, con clara conciencia de su culpa, en un mundo que no puede perdonarlos y que parecen significar, por lo mismo, la ruptura de los valores establecidos.

Montoni encarna en Los misterios de Udolfo todos los valores negativos referidos. Emily, su contrapartida femenina, así lo observa desde su primer encuentro "la dureza y el fuego de su mirada, su orgullo, su tremenda fiereza, su observación atenta, no habían pasado desapercibidas para Emily" (Radcliffe, 2001: 282). Sin embargo, será a lo largo del relato cuando se descubran sus verdaderas y tiránicas intenciones, a menudo por sus actos, pero más frecuentemente en palabras de personajes próximos al mismo. De esta manera sale a la luz su pasado oscuro, sus intenciones de quedarse con la herencia de su esposa o su condición de bandido.

Un paso más lejos dio Matthew G. Lewis al convertir al villano en clérigo'i, un clérigo nada ejemplar, dispuesto a romper sin escrúpulos su voto de castidad. Ambrosio es, sin embargo, un héroe atípico. La complejidad de su retrato psicológico le distingue de sus predecesores villanos inexpresivos; ni el Manfred de Walpole ni el Montoni de Radcliffe adquieren tal grado de perversión (Molina Foix, 2003: 56). En estos dos casos, el villano adquiere esta condición por su ambición y su exceso de energía, pero Ambrosio, abandonado desde niño en un convento y habiendo recibido la más esmerada formación cristiana, llega a poseer tantas virtudes que todo el mundo lo considera un santo; condición que esconde, por otra parte, una enorme hipocresía y presuntuosidad. Ha sufrido una represión sexual tan grande ("Pasa por observar tan estrictamente su voto de castidad, que ignora en qué se diferencia un hombre de una mujer" (Lewis, 2003: 126) y su instinto está tan enterrado en su subconsciente que irremediablemente sucumbe a los primeros ataques de la lujuria, descubriendo que es el sexo y no la religión, porque "afirmar la sensualidad es negar la religión" (Todorov, 1982: 126).

No obstante, no todo en él es libertinaje arbitrario porque al intentar escapar de un papel que le asfixiaba, descubre su verdadero yo; una combinación de libertino, santo, violador, asesino y víctima. Pues no solo es el verdugo de Antonia y Elvira, sino que, a su vez, es víctima de Matilde y finalmente del demonio. Esta característica de Ambrosio pone la primera piedra a una particularidad que puede intuirse ya en algunos villanos góticos, pero que se

\footnotetext{
${ }^{10}$ Este tipo de cura lascivo fue una creación de la sátira clerical de la Baja Edad Media, que luego se extendió a la vida conventual y monástica. La literatura conventual del siglo XVIII, de marcado anticlericalismo propiciado por la Ilustración, que calificaba de estúpidas a las personas que se sometían al celibato, fue sobre todo una invención francesa que luego se extendió a Alemania y en ella se ejemplificaron los vicios del clero y las dificultades de las monjas ingresadas, en contra de su voluntad, para guardar el voto de castidad (Frenzel, 1880: 403-411).
} 
explotará definitivamente en la época romántica, la otredad ${ }^{11}$; una otredad que salvaría el maniqueísmo al que aparecen sujetos los protagonistas de estas novelas y que respondería a la tan señalada cohibición en la mayoría de los aspectos o parcelas de la vida por parte de la Iglesia y del Estado.

Ramos Gómez, en la caracterización del personaje del villano, ha vislumbrado una mayor profundidad y complejidad psicológica al percatarse de la existencia de un viaje de corte iniciático ${ }^{12}$, en la experiencia de este en el discurrir del relato. Se nos describen las vicisitudes y el transcurrir de un ser humano, un verdadero antihéroe que, en su enfrentamiento con las fuerzas que le superan (el destino, entidades maléficas o sus propios instintos sexuales), va a padecer mil penalidades que le conducirán a las puertas mismas del infierno.

Este héroe promovido a la categoría de víctima propiciatoria, podrá ser destruido: el destino exige un precio, y la redención implica un sacrificio. Pero el héroe nocturno triunfa en el momento mismo de su derrota: si la semilla no muere, no dará su fruto; solo la muerte da paso a la auténtica vida (Ramos Gómez, 1988:12).

La iniciación, entendida como aprendizaje, implica un proceso de transición de un estado a otro, esto es, morir o sucumbir para renacer en otro nuevo estado. Así, los protagonistas de estas novelas góticas reviven, tras su muerte redentora o iniciática, pero no son los mismos, un cambio radical ha operado en ellos; más que una purificación debe ser entendido, sin embargo, como una "transfiguración, una transmutación en el sentido alquímico del término" (Ramos Gómez, 1988: 13). Este esquema de pruebas-sacrificio-muerteresurrección se encuentra en la mayoría de los antihéroes de los relatos góticos.

\subsection{La mujer fatal}

Frente al hombre atormentando, dispuesto a dejarse convencer por el demonio y abandonado a las maldades del mundo, se yergue un tipo de mujer, a quien la certeza de hacer el mal llena de una exaltación casi contagiosa. Esta mujer fatal que Keats denominó la "belle dame sans merci" es, asimismo, un elemento indispensable dentro de toda trama gótica. No obstante, el rol que desempeña en estas y el grado de protagonismo que adquiere sufre una evolución dependiendo del tipo de novela de la que estemos hablando. Así pues, la dama cruel (Madame Chenon o la desaparecida signora Laurentini, en Los misterios de Udolfo) de los relatos góticos de corte racionalista, reduce su papel a someter al hombre ${ }^{13}$, la gran parte de las veces su esposo, y a conseguir,

\footnotetext{
${ }^{11}$ La idea de las dos almas, una buena y otra mala, en el pecho del hombre que provoca la lucha del Yo sensual con el Yo moral; todas las hipótesis, interpretaciones, declaraciones angustiosas en orden a un desdoblamiento probado o inminente de la personalidad fueron ampliamente consideradas por el Romanticismo y examinadas a la luz de los nuevos descubrimientos científicos (Frenzel, 1980: 100).

${ }^{12}$ El viaje iniciático ha sido estudiado en profundidad por dos teóricos: Joseph Campbell, en su aún vigente estudio El héroe de las mil caras, y Juan Villegas que recoge el esquema de este y lo aplica a la literatura actual en su obra La estructura mítica del héroe en las novelas del siglo XX.

${ }^{13}$ Existe una palpable diferencia, dentro del propio género, entre unas y otras novelas. La crítica, por ello, ha sometido las mismas a continuas clasificaciones (Molina Foix, Maurice Heine o
} 
por todos los medios posibles, un deseado ascenso en la escala social. Las consecuencias de sus actos, sin embargo, acaban recayendo siempre en su contrapunto femenino, la débil y angelical heroína.

De esta dama, con no demasiadas buenas intenciones, se evoluciona a una mujer perversa, dominante y atroz, agente a través del cual actúa y se manifiesta, normalmente, el diablo. Matilde es, en El Monje, la reencarnación del mal absoluto. Su primera aparición puede anticipar ya su papel dentro del conjunto de la obra. De hecho, cuando Ambrosio trata de convencerla de que abandone el monasterio, ella le pide, en prenda de su estima, que le corte una rosa; rosa que le provoca la picadura de una serpiente que supondrá el inicio de la pérdida de sus virtudes y el camino hacia su condenación eterna.

Si el villano representa al antihéroe que realiza a lo largo de la novela un viaje iniciático que le conducirá a la condenación, esta dama cruel y demoníaca, símbolo de la seducción mortal, representa "las tentaciones dispuestas a lo largo del camino de la vida para impedir la evolución del espíritu y encantar a todo aquel que se cruce en su camino" (Cirlot, 1981: 415).

\subsection{El caballero}

Heredera, como bien sabemos, del ideal bizantino, toda novela gótica necesita, evidentemente, de la figura del apuesto galán que pretende la mano de la heroína. El narrador gótico nos dibuja, pues, un héroe cuyo rasgo más definitorio es la bondad; bondad que aparece siempre acompañada de un físico extraordinariamente agraciado, en clara oposición a la deformación que encontramos en el villano y a la que debe sumarse, asimismo, una valentía sin límites. Todos los caballeros que recorren las páginas de las novelas góticas disfrutan de estos rasgos. Valancourt, el apuesto y misterioso pretendiente de Emily, cumple con la condición de pertenecer a una familia noble de Gascuña, posee una generosidad sin límites y se nos presenta, en palabras del narrador de la historia, como un verdadero modelo de virtud, dado que "había sido educado en todos los conocimientos de su tiempo y tenía un espíritu ardiente y una cierta grandeza de mente que le hacía particularmente brillante en los ejercicios que entonces se consideraban heroicos" (Radcliffe, 2001: 213). En efecto, este tipo de caballero opta por esconder su origen aristócrata porque "quería ser amado por mí mismo, no por ser hijo y heredero del marqués de las Cisternas" (Lewis, 2003: 270). Debido a ello, Don Ramón, marqués de las Cisternas, se presenta, en El Monje, ante personajes y lector, bajo la condición de Alfonso de Alvarado. Sin embargo, su disfraz esconde la pertenencia a una familia de estirpe noble y copiosa fortuna.

\footnotetext{
Maggie Kilgour). En el siglo racionalista por excelencia, la aparición de todo elemento sobrenatural tendría dos posibles explicaciones, la que, por una parte, decanta el fenómeno del lado de la razón, negando su existencia y la que, por otra, reconoce y admite, trasgrediendo los límites de esta razón imperante, la existencia de determinados fenómenos inexplicables. Por eso, preferimos hablar de novela gótica racional, para el primer supuesto y novela gótica irracional para el segundo.
} 


\subsection{La heroina}

El último de los personajes imprescindibles en cualquier relato gótico es la heroína, símbolo e imagen suprema de todas las bondades y virtudes del ser humano, tales como la belleza suma, la candidez o la virginalidad (basadas en el principio de castidad de las novelas griegas antiguas). Walpole fue el encargado de dotar a sus damas con estas propiedades, que si bien no aparecen expresamente detalladas, se sugieren por sus comportamientos y actitudes. Emily, la protagonista femenina de Los misterios de Udolfo, recoge todo este legado del creador del género

En su aspecto se parecía a su madre. Tenía la misma elegancia y simetría en su figura, la misma delicadeza en su comportamiento y los mismos ojos azules, llenos de ternura. Además del encanto de su persona, despedía una gracia cautivadora a su alrededor (Radcliffe, 2001: 20).

No obstante, recordemos, ante todo, que el personaje femenino venía a ser la representación y reencarnación de todos los miedos y temores de la mujer aristócrata de este cambio de siglo y, como tal, debía poseer, asimismo, toda una serie de propiedades que facilitaran el proceso de empatía. De ahí que esta dama goce de las simpatías de las lectoras (Lovecraft, 1989: 2).

Ya no es, por otra parte, protagonista indiscutible, como lo fuera en su contemporánea novela sentimental; aparece, ahora, en un segundo plano a expensas de las maldades del verdadero protagonista, el villano. A pesar de compartir, sin embargo, esta serie de características expuestas, con la dama sentimental (belleza suprema, origen noble o condición de orfandad), se distancia de esta en aparecer sistemáticamente perseguida y ultrajada y en poseer una sorprendente habilidad para sobreponerse a situaciones espeluznantes y para sobrevivir a momentos altamente peligrosos. Vemos cómo el personaje de la gitana vaticina, ya en las primeras páginas de El monje, las desgracias y el asedio al que va a ser sometida su protagonista a lo largo de la historia (Lewis, 2003: 145).

La salva de este agravio o transgresión un héroe con el que aspiraba a casarse desde que tuvo lugar el primer encuentro, pero con el que, hasta el desenlace del relato, no se produce la unión definitiva, dado que siempre se oponen a la misma "obstáculos casi insuperables" (Lewis, 2003: 244). Entre esta heroína y su enamorado debe existir siempre un conflicto de índole familiar y económico que impida su unión, no con una finalidad moralizante, como ocurriera en la novela sentimental, sino con la intención de contribuir a engrandecer sus penalidades y favorecer, asimismo, el suspense narrativo. El final de la novela coincide, entonces, con la recompensa merecida a estas penalidades. De esta manera, "tanto Ramón e Inés, como Lorenzo y Virginia, fueron tan dichosos como pueda serlo cualquier mortal, nacido para ser presa de los infortunios y juguete del desengaño" (Lewis, 2003: 521).

Sin embargo, aunque el terror la paralice y confine, la heroína logra siempre sobreponerse, explicar los fantasmas o retener su integridad. Los personajes femeninos, entonces, nunca quedan del todo confinados a la razón del hogar ni 
el Mal logra hacerse del todo externo. Es más, la dama, afirma María Negroni, al acceder a las profundidades del castillo se encuentra por primera vez "con ciertas dosis de felicidad, tenebrosa y magnífica, es cierto, pero la más digna de las felicidades, la que concede la libertad", y ello porque esta mujer prefiere morar cerca del mal, dado que allí, al menos, está a salvo de toda aquella rigidez ideológica de lo institucional. No se trata, por lo mismo, y en contra de lo sostenido por la mayoría de la crítica, de un personaje del todo plano; muchas de las mujeres que recorren estas novelas presentan ya pequeñas dosis de profundidad psicológica, "una constante vacilación entre tragarse el mundo y trabajar hacia el desvío, entre el deseo de diluirse y la beligerancia que arrecia" (Negroni, 1999: 220); se anticipan, así, a la fuerza de los personajes que encontraremos posteriormente en las obras románticas.

Las particularidades de la heroína gótica, dentro de los tópicos generales que deben cumplir, presentan, sin embargo, ciertas disimilitudes de acuerdo al tipo de novela cultivada por el escritor que dibuje sus perfiles.

Así pues, frente a las doncellas virginales y supeditadas a las decisiones del varón de las novelas góticas irracionales, las heroínas del llamado gótico racional y, en concreto las trazadas por Ann Radcliffe (Emily o Julia) se caracterizaban por su amor a la naturaleza y a la verdad, pero también por su sinceridad, su humildad, su ternura y su simplicidad (en el fondo, futuras marcas victorianas de la mujer, más que rasgos de una figura femenina de la época de la emancipación), que partían del esquema de la novela aristocrática de la virtud recompensada, pero girando siempre en el vacío, pues "la virtud femenina del decoro" aún no había encontrado su sitio en estos nuevos escenarios góticos. Las lágrimas de emoción o de miedo, los enrojecimientos o los desmayos se convierten, asimismo, en elementos comunes a la hora de caracterizar a este tipo de damas.

En definitiva, dentro del maniqueísmo imperante en las novelas góticas, la dulce y agraviada heroína vendría a desempeñar, frente a la visión diabólica de la mujer que prima en otros personajes femeninos, una visión esperanzada, benéfica y redentora del ser humano.

\subsection{El narrador}

El narrador, como sabemos, es una entidad que crea el autor a quien este cede la palabra para, entre otras tareas, revelar los hechos, presentar a los personajes o ubicarlos en un tiempo y espacio concretos. Viene a ser el autor implícito, el "alter ego" del autor del texto. Para entrar en el relato, el narrador recurre a una serie de máscaras a través de las cuales intenta mantener a salvo su credibilidad y, en definitiva, la verosimilitud de la historia. Funda, por ello, toda su autoridad en el testimonio personal de un testigo directo de los hechos, bien en calidad de protagonista o de simple observador.

El narrador de la novela gótica, en concreto, no deja de ser un narrador de corte tradicional, un narrador omnisciente que controla todos los elementos de la diégesis. Puede ser un personaje central o bien aparecer solo al comienzo para iniciar el relato, rematándolo a veces al final. 
Este narrador, sin embargo, sabe que el carácter insólito de su historia le impedirá ser creído, por ello, se guarda de ser demasiado afirmativo y dirige hacia sí mismo las objeciones que presiente en los demás. No pretende resolver el problema que expone, simplemente mostrarlo, para que sea conocida esa terrible y espeluznante experiencia. Es un narrador pefectamente informado, ahora bien, esta facultad que le dota de cierta superioridad, no reside tanto en su saber extraordinario, como en el conocimiento de su limitación. De hecho, abundan las señales de interrogación y se tiende a rechazar toda aserción definitiva.

Según algunos teóricos, como es el caso de Todorov, la utilización de la primera persona es la única característica fundamental de las narraciones fantásticas y, por lo mismo, de este tipo de relatos góticos (Todorov, 1982: 101103). No obstante, a pesar de que la primera persona enriquece las novelas góticas y las cubre de matices, la mayor parte de las mismas se muestran en palabras de un narrador externo a los hechos. Al utilizar el punto de vista de un narrador externo, esta técnica muestra, aparentemente, una realidad objetiva. En efecto, los relatos en tercera persona suponen un personaje que experimenta más o menos pasivamente los acontecimientos, no tiene conciencia de la realidad, o la tiene demasiado tarde. La utilización del punto de vista omnisciente otorga total libertad al narrador para contar la historia sin someterse a las limitaciones que conlleva narrar tan solo lo vivido directamente.

Este narrador de la novela gótica se caracteriza, asimismo, por la tendencia a la trampa. G. Philippe habla de "defective narrator" (1996: 83), un narrador tramposo que nos oculta lo que sabe. Finge narrar los hechos día a día, pero sitúa la acción en el pasado, con lo cual estamos ante un efecto de suspense creado por la focalización interna. Simétricamente, la narración tramposa impondrá, según sostiene este estudioso, un tipo de lectura que es la relectura, pues el lector modelo solo puede entender la historia narrada volviendo sobre sus pasos y reinterpretando las escenas que le han sido referidas.

Así, Emily, en Los misterios de Udolfo, deberá descubrir un secreto (el extraño retrato que besa su padre, la mujer desaparecida en el castillo o la habitación a la que se prohíbe la entrada) que se le presenta disperso, fragmentario, quimérico, en una búsqueda hermenéutica que prefigura la del propio lector y constituye el verdadero proceso de la novela, siempre en relación con la estructura iniciática que presentan estas obras.

\section{Coordenadas espacio-temporales}

Las coordenadas espacio-temporales de una novela, no pueden ni deben ser estudiadas, desde la perspectiva teórica actual, de manera autónoma, como departamentos estancos entre los que no existen relaciones. Ya Coleridge había apreciado, en el caso de las novelas de El Siglo de las Luces, una relación aún más estrecha que en sus predecesoras entre estas coordenadas. Sin embargo, no sería hasta la publicación de la obra Teoría y estética de la novela (1975) por el formalista Mijail Bajtin cuando esta intuición queda definitivamente 
sistematizada. Su término cronotopo $^{14}$ supuso un acercamiento del todo novedoso a la interpretación de ambos elementos narratológicos. Al demostrar una afinidad, una dependencia entre las mismas, pretende, este autor, explicar las fronteras entre géneros y el nacimiento de los nuevos subgéneros literarios, pues "el género y sus variantes se determinan precisamente por el cronotopo" (Bajtin 1989: 238). Su reflexión abriría el camino a la consideración de un subgénero: la novela gótica, nacida de la especial conexión entre ambas coordenadas.

Entendida esta unión indisoluble, no debemos olvidar que el tiempo y el espacio que nos presentan estas novelas son radicalmente opuestos a los que podemos hallar en los textos considerados canónicos. Las coordenadas espaciotemporales en las narraciones góticas tienden, como veremos, al fragmento y a la deformación, lo que conlleva que acaben por infringir la ley de la claridad, relacionada directamente con el hasta entonces irrefutable principio aristotélico de verosimilitud. Sin embargo, nosotros, siguiendo a estudiosos como Julia Barella, entendemos que la verosimilitud de los hechos narrados está dentro de la categoría de la lógica interna del relato, sea cual sea el género literario que se trate. Es decir, que dentro de la categoría de la literatura gótica, como perteneciente a la literatura fantástica, serán verosímiles los acontecimientos que se desarrollen en el marco de estas distorsionadas coordenadas espaciotemporales (Barella, 1994: 14). Así pues, como dijéramos anteriormente, lo verosímil no tiene por qué oponerse a lo fantástico, sino que se entiende como un criterio más amplio que depende del género literario que estemos estudiando.

\subsection{El espacio narrativo}

El espacio, como sabemos, es un elemento estructural cuya finalidad no se reduce a ser el ámbito en el que se desarrolla la acción, sino que ayuda a configurar los rasgos psicológicos de los personajes, influye en sus conductas y se erige en definitorio de este tipo de narraciones. De hecho, la descripción del espacio en los relatos góticos adquiere una importancia fundamental.

Se trata de un espacio histórico que se transforma en un lugar esencial, más protagonista que telón de fondo o marco de la escena de estas novelas. Los escritores góticos nos describen, entonces, un mundo de pesadilla donde las construcciones no cobijan, sino que encierran y donde los caminos o pasillos no conducen a ninguna parte, sino que están trazados para confundir y perder a todo aquel que los recorre. De ahí la importancia de las descripciones dentro de estas novelas de los lugares donde se sitúa o va a situarse la acción.

Desde el punto de vista estético, Kant lo calificó de espacio terrorífico, repleto de lóbregas encinas, alamedas sombrías y secretas, tétricas sombras,

\footnotetext{
${ }^{14}$ Bajtin define cronotopo como "la unión de los elementos espaciales y temporales en un todo inteligible y concreto. El tiempo se condensa aquí, se comprime, se convierte en visible desde el punto de vista artístico; y el espacio, a su vez, se intensifica, penetra en el movimiento del tiempo, del argumento, de la historia. Los elementos del tiempo se revelan en el espacio y el espacio es entendido y medido a través del tiempo."(Bajtin, 1978: 237-238).
} 
luces tenebrosas, y todo envuelto en una oscuridad espeluznante, fría, casi apocalíptica. Burke, también en esta misma línea, habla de un espacio determinado por la intersección de una serie de elementos imprescindibles, sin los cuales, no se podría caracterizar cierto texto como perteneciente a este género; inmensidad, infinidad, oscuridad, soledad o brusquedad como elementos constitutivos de lo sublime, determinan el espacio de estas novelas convirtiéndolo en espacio estético ${ }^{15}$. Una escenografía, extrema, cercana a la teatralidad, la misma boca del infierno ${ }^{16}$ y algo más que un marco físico: el escenario en el que está representada la tensión, a menudo dramática, entre la sublimidad de la naturaleza y la limitación del espíritu humano.

Lo gótico, por otra parte, condensaba, en rigor, lo que se suponía había sido el pasado medieval inglés y precisamente los signos más representativos de aquel remoto pasado eran dos espacios cerrados, casi herméticamente, y de los que, por lo mismo, la huida se antojaba del todo imposible; en efecto, el castillo en ruinas y el convento, mundos aparentemente finitos, pero que se descubren como arquitectura inagotable, van a erigirse como símbolos de esta nueva estética, elementos indiscutibles de lo sublime.

Sin embargo, y a pesar de que se basaron esencialmente en estos dos espacios, emblemas indiscutibles del pasado medieval inglés, situaron la mayor parte de las novelas en ambientes latinos, en territorios a orillas del mediterráneo, al condensar, en esencia, todos los miedos y temores de la sociedad aristocrática anglosajona, porque vieron en estos países no la luz grecolatina, sino la oscura e inquietante sombra de un pasado tenebroso. Italia y España, se convertirán entonces, dentro de esta imaginería, en espacios góticos por excelencia. De esta manera, Lewis sitúa su historia en España, concretamente en Madrid, un mítico Madrid gótico, decadente e hipócrita, "una ciudad donde la superstición reina con tan despótico rigor" (Lewis, 2003: 115).

En estrecha relación con la obsesión, ya señalada, por el pasado que comenzó a proliferar en las últimas décadas del siglo XVIII, debemos situar la obsesión de esta literatura por el espacio cerrado del castillo ${ }^{17}$. El castillo, casi siempre en ruinas y en medio de un paisaje desolado y yermo, no domesticado $\mathrm{y}$, por lo tanto, sublimemente incomprensible, "Mas que un decorado, era la evidencia de que no hay construcción que no lleve en sí misma el germen de la

\footnotetext{
${ }^{15}$ En el ensayo titulado The Supernatural in Poetry, Ann Radcliffe, enumeró también con bastante detalle los lugares o paisajes que debieran convertirse en motivo literario dentro de la novela gótica, apoyándose en figuras de la talla de Shakespeare y Milton, que aprovecharon al máximo los recursos que este les ofrecía.

${ }^{16}$ En la escenografía gótica se percibe, con claridad, la influencia de los grabados del pintor Giovanni Battista Piranesi. Nos encontramos con el mismo mundo arquitectónico carente de puntos de referencia del castillo gótico. Praz llega a afirmar, incluso, que habría sido la visión de una de sus cárceles lo que inspiró a Walpole el sueño que concibió su novela (Praz 1970: 17).

${ }^{17}$ El mismo iniciador del género Horace Walpole, habiendo soñado su propio castillo medieval, se retiró al área de Strawberry Hill, con el fin de convertirlo en realidad; y de su castillo soñado nació toda la escenografía que ya nunca habría de abandonar el género: estancias oscuras y claustrofóbicas, chimeneas inspiradas en las tumbas de las grandes catedrales, ventanas en forma de rosetas, paredes de seda de damasco plagadas de nichos, techos tapizados en terciopelo escarlata, pequeñas criptas donde reposaban estatuas o armaduras de caballeros andantes.
} 
propia destrucción" (Molina Foix, 2003: 13). Un entorno cerrado como epítome del aislamiento feudal ${ }^{18}$ y símbolo de la diferencia histórica entre el pasado imaginario y el presente de la narración, que se convertirá en marco idóneo para situar sus tétricas y siniestras tramas, pues, no olvidemos, que los castillos y sobre todo los castillos en ruinas solían, o al menos esto afirmaban multitud de comentarios supersticiosos, estar frecuentados por fantasmas.

El castillo aparece, entonces, como una prisión, como coacción de la libertad de la protagonista. Y es por ello por lo que la crítica ha vinculado estrechamente el castillo gótico a las emociones y experiencias individuales de los personajes, "como dos caras de la misma moneda, por la que el tiempo anímico se transmuta en un espacio simbólico" (Amicola, 2002: 52). De hecho, en esta misma línea, Julia Kristeva habla del castillo gótico como una metáfora proyectada de una alucinación; es decir, una representación en piedra de los torturados y oscuros recovecos de la mente civilizada porque en su estructura podemos reconocer "las criptas y sótanos del deseo reprimido, y las torres y campanarios de la neurosis" (Kristeva, 1980: 58-59).

Resulta interesante destacar, asimismo, para ahondar más si cabe en su trascendencia, el hecho de que la gran parte de las novelas calificadas como góticas llevasen por título el espacio donde se desarrollan ${ }^{19}$. Se debe, en gran medida, a que el castillo aparece como centro de la mayor parte de la novelas góticas, como hilo conductor de los destinos y designios de los personajes que lo habitan. Este castillo, aislado e inquietante, implicaría, para Lovecraft, una serie bien definida de elementos concretos para la escenificación del horror: "húmedos corredores, malsanas catacumbas y un sin número de leyendas y fantasmas estremecedores [...] luces extrañas, trampas húmedas, lámparas apagadas, manuscritos ocultos y mohosos, goznes chirriantes y tapices que se estremecen (Lovecraft, 1989: 21-22). Dentro del espacio general, entonces, estos pequeños elementos escenográficos adquieren una importancia determinante; desempeñarían la función de acentuar dentro de la estructura de la novela gótica "su carácter de rompecabezas, de calidoscopio, de juego de formas literarias y arquitectónicas que se superponen y transponen provocando que el orden y la unidad (factores que definían la novela Iluminista) dejen de ser los valores de referencia" (Molina Foix, 2003: 23).

Así, Los misterios de Udolfo de Ann Radcliffe transcurre en un castillo perdido de los Apeninos, rígido por fuera, laberíntico e inestable por dentro "aunque estaba iluminado por la puesta de sol, la grandeza gótica de su arquitectura y sus muros de piedra gris oscura, le daban un aspecto sublime y sombrío" (Radcliffe, 2001: 399). Udolfo, como todo castillo gótico desde que Walpole recuperara para la posteridad Otranto, es, en definitiva, más que una sinécdoque de la noche, una representación de todas las angustias y opresiones

\footnotetext{
18 Simbolizaba la opulencia y la hegemonía de un poder feudal venido a menos, así como la opresión con que se sujetaba al súbdito, especialmente a la mujer y a los considerados inferiores.

19 Destacan estos títulos, sobre todo, si se establece una contraposición con el resto de obras calificadas como "novelas" que ya empezaban a forjarse en diversos estados del viejo continente.
} 
de una sociedad cuya luz no era tan fuerte ni tan purificadora de conciencias como sus impulsores intentaban hacer creer.

Este espacio, primordial y prácticamente indispensable para hablar propiamente de novela gótica, amplía sus horizontes de la mano del reformador del género, Lewis. Bien es cierto que el monasterio, en sus más diversas variedades de abadía, convento o hermandad, aparece siempre como lugar obligado en la creación de todo espacio gótico. Sin embargo, nunca adquiere un papel protagonista hasta esta novela referida, simplemente viene a representar el espacio de la protección; espacio al que se encomiendan los diversos personajes que huyen de las maldades del protagonista.

No obstante, el renovado villano de Lewis, ahora en el papel de monje, precisa un evidente cambio de escenario. Así pues, el convento, junto con el castillo encantado, pasará a convertirse, de la mano de este escritor, en un nuevo escenario gótico donde desarrollar estas terroríficas tramas.

El espacio de las novelas góticas, sea este un convento o un castillo, presenta la particularidad de ser siempre doble: el espacio de la protección, por un lado, y el espacio de la opresión, por otro. Espacios que no solo no están predispuestos de antemano, sino que son cambiantes a lo largo de todo el relato, complicando más la estructura e incidiendo en las penalidades a la que se ven sometidos los protagonistas. Los límites no son fijos ni evidentes, transformándose de pronto ante el horror de los personajes. Sin embargo, el lector ya sabe de antemano que ciertos lugares, dentro de los mismos, no presagian nada bueno, porque los reconoce como escenario de sus miedos nocturnos. Este es el caso de los subterráneos, las habitaciones secretas, los cementerios y las criptas.

En suma, nos encontramos ante un espacio sumamente complejo, primordial, y determinante; la misma razón de ser de las novelas góticas.

\subsection{El tiempo narrativo}

El tiempo externo de la novela gótica es siempre pasado, remoto y oscuro, siendo en la mayoría de las ocasiones un pasado medieval que, por lo general, nunca aparece determinado con precisión. El Monje y en El castillo de Otranto son una buena muestra de ello. La fecha exacta, en un intento de generalización, permanece siempre oculta a los lectores. El propio Walpole en su Prólogo a la primera edición de la obra precisa:

Si el relato se escribió en las fechas en que se supone que ocurrió, debió de ser entre 1095, la época de la primera Cruzada, y 1243, la fecha de la última, o no mucho después. No hay otras referencias en la obra que nos permitan adivinar el período en que transcurre el relato (Walpole, 1982: 15).

El empleo del tiempo interno, por su parte, adolece de alguna de las propiedades de las primitivas novelas griegas, de la misma manera que lo hiciera en el dibujo de los personajes y en la disposición del argumento. Así, el tiempo durante el cual se desarrollan las múltiples aventuras de sus 
protagonistas no es calculado en la novela "son simplemente días, noches, horas, momentos, medidos solo técnicamente en los límites de cada una de las aventuras." (Bajtin, 1989: 243). Sin embargo y a pesar de que la novela gótica está construida sobre la base del tiempo de la aventura de tipo griego, no es imprescindible que todos sus componentes se manifiesten para crear este efecto, basta con que "un cierto elemento de ese tiempo se implique en otras series temporales para que aparezcan inevitablemente los fenómenos que los acompañan" (Bajtin, 1989: 249).

No obstante y coherentemente con lo expuesto, la novela gótica en un paso más en la delimitación del cronotopo rompe, del mismo modo que lo hacía con la espacial, con la continuidad de la coordenada temporal ${ }^{20}$, al presentarnos una serie de tiempos internos inconexos entre sí, en palpable oposición a los textos promovidos por el Iluminismo. El tiempo interno se complica; no es presentado de forma lineal, llegando a ser, incluso, contradictorio:

[...] se invoca con tal fuerza la tiranía del pasado (maldiciones familiares, supervivencia de despotismo y superstición) que se acaba por reprimir las esperanzas del presente [...] y haciendo estallar la dimensión temporal en que se inscribe, afirma un presente inmóvil: el tiempo se paraliza, se anula, se abstrae, se hace espacio cerrado (Molina Foix, 2003: 18).

Este complejo uso del tiempo interno se debe, asimismo, a que en la caracterización de la novela gótica adquiere especial relevancia lo que Garrido Domínguez denomina tiempo psicológico. Señala este teórico que "la vivencia del tiempo varía de un individuo a otro según su estado de ánimo o según sea la huella que determinados hechos han dejado su memoria [...] De acuerdo con ellos, el tiempo se expande o se concentra, adquiere espesor o se diluye" (Garrido Domínguez, 1996: 158). Los personajes que recorren estas novelas no tendrán la misma percepción del tiempo según el grado de cercanía que presenten con respecto al acontecimiento sobrenatural. Las vivencias de la heroína, testigo directo de todos estos sucesos, desbordarán holgadamente los límites del tiempo convencional, al sentir el peso de unos minutos que su angustioso miedo ha convertido en eternos; circunstancia esta que apreciamos en el caso de Emily, quien en los minutos siguientes a una espeluznante visión, siente que "las horas no han pasado". El tiempo, en definitiva, no tiene por qué ser único, porque, de hecho, no es idéntico para todos.

También los sueños premonitorios y las sucesivas apariciones espectrales pueden provocar distorsiones en el empleo del tiempo narrativo (Ramos Gómez, 1988: 150). Vemos, de esta manera, cómo el futuro puede intervenir en el presente o cómo el pasado puede hacerse más fuerte y real que el propio presente vivido, imponiéndose a este. La aparición en El Monje de la Monja Ensangrentada, por ejemplo, supone una profunda modificación del eje temporal. De hecho, por naturaleza, la aparición de todo fantasma implica, ya de por sí, la interferencia del pasado en el presente. Esta visita cada noche a Ramón de las Cisternas diciendo lo mismo y haciendo lo mismo que la noche

${ }^{20}$ En general puede afirmarse que la conciencia del tiempo no se da en la literatura hasta el siglo XVIII. 
que precedió y la que seguirá. El tiempo queda suspendido ("hasta entonces todas las facultades de mi cuerpo habían estado en suspenso" (Lewis, 2003: 266), afirma aterrorizado el personaje) en un eterno presente que vuelve sobre sí mismo permitiendo, encuentros insospechados entre los que murieron antaño y los que aún habitan en la tierra de los vivos y, contribuyendo a la sensación de obsesión que padecen los protagonistas y, por ende, los lectores.

No tomar en consideración esta especial percepción del tiempo es condenarse a no encontrar una explicación satisfactoria y coherente para muchas de las aparentemente anomalías que se encuentran en las páginas de los relatos góticos. Solo entendido de esta manera podemos comprender que el tiempo quede, en ocasiones, suspendido, de saltos, se alterne o se prolongue mucho más allá de los límites que se cree posible, convirtiéndose, a veces, en protagonista, en verdadero artífice y causante de la transgresión.

\section{Conclusiones}

Es sabido que cuando las batallas ideológicas pierden el motivo de la lucha inmediata de la que surgieron, aquellas manifestaciones combativas a las que dieron lugar acaban por perder lo que en su momento las hacía prestigiosas $\mathrm{y}$, por lo mismo, empiezan a ser desvinculadas de los elementos que les dieron razón de su existencia. Alejada del contexto que la permitiera nacer, la novela gótica, entonces, quedó relegada al cajón de la subliteratura, acusada de trivial y absurda, por sus detractores primeros.

A pesar de todo, la reivindicación de un género, que fuera semilla de gran parte de la literatura que se gestó en los años posteriores a su nacimiento y cuya influencia se puede rastrear incluso en manifestaciones literarias actuales, bien merece la atención que comienza a serle prestada en los últimos tiempos y a la que pretendemos contribuir con la sistematización de la teoría del género que hemos llevado a cabo no solo en el presente trabajo sino por medio de ulteriores investigaciones.

\section{BIBLIOGRAFÍA}

AMICOLA, J. (2003): La batalla de los géneros: novela gótica versus novela de educación, Rosario, Beatriz Viterbo Editora.

CASTLE, T. (1995): The Female Thermometer. XVIIIth Century and the Invention of the Uncanny, New York, Oxford University Press.

CLERY, E. J. (1995): The rise of supernatural, Cambridge, Cambridge University Press.

BURKE, E. (1757): Indagación filosófica sobre el origen de nuestras ideas acerca de lo sublime y lo bello, Alianza Editorial, Madrid, 2005.

ESTEBÁNEZ CALDERÓN, D. (1999): Diccionario de términos literarios, Madrid, Alianza Editorial (Colección Filología y Lingüística).

FRYE, N. (1968): A study of English Romanticism, Nueva York, Random House. GARRIDO DOMÍNGUEZ, A. (1996):. El texto narrativo, Editorial Síntesis, Madrid.

JACKSON, Rosie. (1981): Fantasy, the literature of subversion, Nueva York, New Accents. 
KANT, E. (1984): Lo bello y lo sublime: ensayo moral y estético, Madrid, Austral. KILLEN, A-M. (1967): Le roman "terrifiant » ou roman "noir » du Walpole à Anne Radcliffe et son influence sur la littérature française jusqu'en 1840, París, Champion.

LOVECRAFT, H. Ph. (1984): El horror en la literatura, Madrid, Alianza.

MOLINA FOIX, V. (2003): El Monje (prólogo), Madrid, Cátedra.

PENZOLDT, M. (1952): The Supernatural in Fiction, Londres, Meter Nevill.

RAMOS GOMEZ, M. T. (1988): Ficción y fascinación: literatura fantástica prerromántica francesa, Valladolid, Universidad, Secretariado de publicaciones, D.L.

ROAS, D. (2001): Teorías de lo fantástico, Madrid, Arco libros.

ROAS, D. (2006): De la maravilla al horror. Los inicios de lo fantástico en la cultura española (1750-1860), Pontevedra, Mirabel Editorial.

TODOROV, T. (1982): Introducción a la literatura fantástica, Barcelona, Ediciones Buenos Aires.

\section{Corpus utilizado}

LEWIS, M. G. (1796): The Monk; Traducción de Molina Foix, V. (2003): El Monje. Madrid, Cátedra.

RADCLIFFE, A. (1794): The mysteries of Udopho; Traducción de Costas Solano, C.J. (2003): Los misterios de Udolfo, Madrid, Valdemar.

WALPOLE, H. (1764): The castle of Otranto; Traducción de Praz, M. (1982): El castillo de Otranto, Madrid, Bruguera. 